\title{
Multimedia Inquiry
}

\section{One Fish, Two Fish; Red State, Blue State}

\section{Brett Ommen}

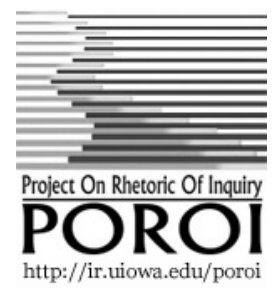

Poroi, 5, 2, November, 2008

Add this to the endangered list: blank spaces.

$$
\text { - Louise Story (2007) }
$$

1 Writing for the New York Times, Louise Story offers this useful, if brief, news bite to the American people. The reason that Story can add blank spaces to the endangered list is because advertisers have been adding images everywhere they can. Story details the extent of these visual additions by way of eggs, turnstiles, take-out containers, and airplane sick-bags. This intrusion of images into the otherwise blank spaces of public life is not unique; in fact, it seems entirely probable that it merely illustrates the fundamental characteristic of our increasingly visual cultures. Images go where they want, and they typically want to go anywhere they can. Of course, images do not find their way onto blank surfaces by themselves but by way of what Walter Benjamin articulated as humanity's "need for sensation" (1999, pp. 65-66). Given the vast number of people that circulate in public space, it seems only logical that images would find their way onto the vast number of surfaces that border, direct, or otherwise offer themselves up to public experience.

2 Typically the account of the expansion of visual surfaces gets discussed in institutional terms. The blank spaces that Story recalls face extinction at the hands of advertising agencies and commercial interests. But the rise of visual displays in public space occurs in significantly more banal ways as well. The need for sensation detailed by Benjamin was driven by humanity's need not merely to see but also to show. A focus on the institutionalized modes of visual production distracts critical attention to the conditions of circulation and experience that drive visual practices. To the extent that the production of images occurs in spaces apart from visual experience, display and circulation become more immediate forces in visual cultures. They create a space for public activity to the extent that individuals not only see images but also offer them up to the vision of others.

3 The preponderance of commercial images is not necessarily incidental to these visual practices of display. This is because the increased prevalence of display surfaces occurs as part of consumer culture and in addition to it. The commercial impulse of many a visual practice is significant, not because the content is commercial, but because consumer capitalism provides a 
foundational logic for visual practices generally. Visual images come to serve as a primary means for communicating ideas in spaces that are marked by the tension between private and public interests. Such spaces and the visual practices that mark them serve as intellectual spaces for investigating how individuals manage their self-understandings as private and public subjects - how they negotiate their senses of subjectivity under current conditions of liberalism.

4 "In liberal thought," Michael Warner explains, "private persons, no longer defined by privation or powerlessness, had become the proper site of humanity. They possessed publicly relevant rights by virtue of being private persons" (2002, p. 39). Liberalism demands a negotiation between the security of private identity and the scrutiny of public identity. At times, says Charles Taylor, such a condition is explained "as the rise of 'individualism' at the expense of 'community.' As a result, we fail to recognize that the inevitable flip side of the new understanding of the individual is a new understanding of sociality: the society of mutual benefit, whose functional differentiations are ultimately contingent and whose members are fundamentally equal" (2002, p. 99). The result is a form of publicity marked by negotiating individual identity in decidedly public spaces, empowering visual practices in distinctive ways.

5 The empowerment holds for images produced institutionally as well as images displayed by private individuals, even as the slick and enticing production values of commercial images draw critical attention away from visual practices in everyday life. Typically, visual scholarship attends to the influence of advertising on publics and their discourses, but it slights as seemingly anecdotal the more banal visual practices of everyday life. For example: displaying images on privately-owned automobiles. Here I have in mind not the words that dominate conventional bumper stickers but such images as the Christian ichthus (fish) in Figure 1 and the looped ribbons in Figures 7-11. Such visuals provide little information in and of themselves, but these simple images achieve great variation and circulation. To the extent that rhetorical inquiry focuses on the singular image, it needs a singularly impressive object. A study of visual practices, in contrast, relies less on the impressive nature of the single image and more on the magnitude of display.

6 The shift to conventions of display enables us to investigate how brief visual experiences of individuals can illustrate larger practices of publics. The Christian ichthus or its imitators might express something particular, but such images become publicly significant in their display and circulation as parts of broader visual practices. The same can be said of looped ribbons. An individual ribbon might express support for a specific cause, but it becomes more interesting when considered in conjunction with its many variants in circulation. Images have traction individually as communicative objects, yet 
further communicative effects arise from shared spaces of display and circulation. To combine ichthus variations with ribbon variations can produce even richer visual practices. Not passively seen but actively displayed, images mirror and inform public discourse in general.

7 On their own, images such as the ichthus and the ribbon seem like personal statements, probably interesting ones. Yet a rich tapestry of similar images can amplify and alter such statements through a shared logic of display, a normalized visual practice. The tapestry of display and circulation can develop into a mode of public discourse as it reflects and informs more overtly political discussions.

8 The analysis to come targets the formation of seemingly minor images into a mode of communication that extends beyond any visual focus on one image at a time. Fish and ribbons, even political maps, might each communicate on their own. But understood together as a visual practice, such images currently form a prominent public discourse that speaks to our understanding of the liberal subject.

\section{Indexical Visual Culture}

9 Skeptics of anything akin to visual publicity often formulate their objections in one of two ways. The communicative critique says that images lack the precision typically demanded of public discourse, because complex compositions of images encourage diverse and subjective interpretations. The public critique says that viewers get only a passive role, because images are mere, unresponsive materials - even in complicated combinations.

10 The critiques may be fair for some images, but they miss the diversity and contingency of our visual practices. Rhetoricians should analyze the practices of visual cultures more than the meanings of individual images. Our work should emphasize how displays use images. One of our visual practices features advertising and logo creep, and it is pervasively commercial. But it is not the only visual practice; another of our visual practices uses simple images from these or other sources as place holders for identities, and it is shaping our understanding of publics. These images are indexical in regulating their meanings by contingent connections between the signs and their referents.

11 This sense of indexical departs from Charles Saunders Peirce, who defined the index as "a sign which refers to the Object that it denotes by virtue of being really affected by that object" (1940, p. 102). For Peirce, an index is a sign that gains its meaning by evidencing a physical or temporal act. Thus its meaning is contingent only in narrow way - on the physical work that an 
object performs to create the sign.

12 But Roman J akobson expanded the contingency of the index in meaning production. He appealed to pronouns to complicate Peirce's sense of the index. The "I," according to J akobson, becomes an index for individual identity in speech, designating the individual in particularity. "The variant meaning of the pronoun dependent upon the context (a Grundbedeutung) makes it indexical (or pragmatic)" (Caton 1987, p. 236). In this way, the index is a sign that finds meaning in its contingent placement in a broader discursive practice. The indexical image takes advantage of this more expansive and nuanced contingency. No longer just a function of the contingent relation between the object and the sign, the index is meaningful in the contingent relation between the sign and its mode of existence in use: its characteristics of display and circulation as implied by its presence in shared spaces.

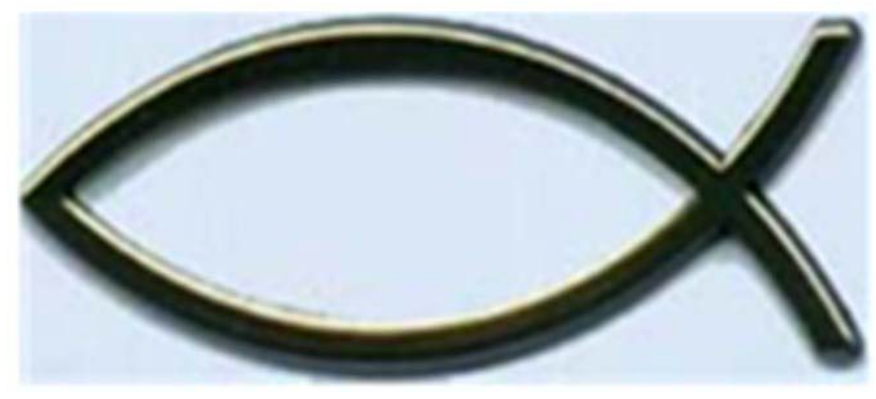

Figure 1

13 The ichthus shows this. It began as a way for early Christians to identify each other. Meeting a stranger, a Christian might scuff a single arc on the ground. Fellow Christians would know to complete the fish by drawing a second arc. To others, the Christian would seem to be fidgeting idly in the dust. In our time, the ichthus has become highly visible on various automobiles. For Peirce, the ichthus could be a fish icon, an index for mechanical stamping, or alternately a symbol to the extent it operates as a message that is not about fish or mechanical reproduction. But for J akobson, the ichthus could be meaningful precisely because its form is found in regularized places and reveals a willed choice of display. These contingent conditions of circulation and display are crucial for two reasons. First, the image circulates in public life through broad and active display, showing the visual practice to be widely accessible. Second, the marker is no longer a covert invitation to identification but an overt statement of identification. As a car placard, the ichthus is an indexical reduction for characteristics of Christianity, making it an efficient way to identify publicly as Christian. 
14 Indexical operation of images can be crucial once they circulate publicly. Arguably there is no primary relationship between the fish image and Christianity, because nothing about the fish embodies characteristics of Christianity as the crucifix does. So the fish image is merely an index, a simplified marker of something more complex that becomes recognizable from its contingent circulation. In its reduction and circulation, the index offers a particular identification for people who display the image.

15 In turn, the new display extends a new invitation. Early display of the ichthus was partial and mutual, depending on a second person for completion. The car ichthus is fully formed, and it invites identification in a vast variety of ways. An example is the readily identifiable Darwin fish.

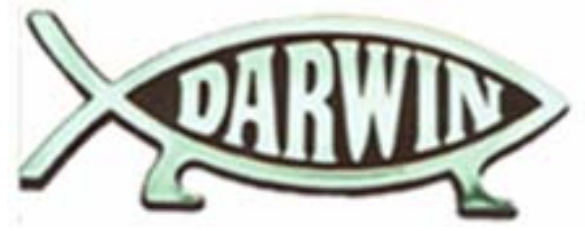

Figure 2

The original framework of remains, marking the Darwin fish as a continuation of the ichthus; but now it has legs, a single tail, and Darwin's name within.

16 As a response to the ichthus, the Darwin fish shows visual practices capable of reflection, even deliberation. The process is referential, though not reverential. As an indexical image that invites further interactions, the Darwin fish creates a second-order reduction of the ichthus. On its own, the ichthus represents a Christianity without clear characteristics. Once the Darwin fish circulates with the same indexical template in the same space, the ichthus gets narrower as a Christian marker - of creationism only.

17 Tom Lessl has argued that, "by inserting Darwin's name into the place on the fish icon usually reserved for Christ, the Icthus symbol is ritually profaned, which is to say, emptied of its religious meaning" (2001). Refining this, Lessl has said that the Darwin fish "appears to appropriate the role or identity that this traditional symbol represents." Alterations of the Darwin fish, he adds, "call up from the past those values that the scientific culture has inherited from the Christian narrative" (2007, p. 133). Lessl might be correct; but it seems equally possible that, once the ichthus becomes an overt public practice of identification, the indexical operation becomes equally public. Whatever religious meaning the ichthus had yields to an instrumental logic of identification. 
18 Once indexical images circulate publicly, they empty of particular meaning and become tools for reducing identities into displayable images. Such reduction limits the capacity for nuanced visual responses to competing indexical markers. Once the Darwin fish enters into the same circulatory field as the ichthus, the original fish cannot be anything but creationist. Later variations on the ichthus show this.

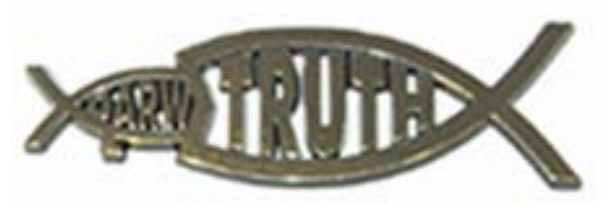

Figure 3

19 There is no indexical way to respond to the Darwin fish with a complicated argument about a Christianity that accepts evolution. What moves remain? The Truth fish (Figure 3) marks the authority of one identification over another by degrading (in this case, devouring) the Darwin index by way of a larger ichthus. Thus it confirms the accusation of the Darwin fish that the ichthus is a form of creationist identity and gives the ichthus template a chronology: for any single instance of the template to make sense, we have to imagine them in a particular order regardless of when they were put on display. Each variation trades on the availability of the template, and each new variation compounds the visual reductions.

20 Indexical images reduce meanings because the visuals are streamlined but also because we process the simple visuals in a further simplifying and totalizing way. Viewers perform a kind of vision that endorses the witnessed reduction as an assessment that is complete, concise, and wholly accurate. Lacan explains the sense of completion as a function of the human primacy of the eye (1981, p. 81). In indexical practices, the premise is that visual experience privileges individual viewers as owners of the representations. We experience this, writes Gadamer, as resonance between the image and our "self-understanding" as individual viewers (2000, p. 185).

21 Indexical experiences are complete in the moment of viewing because this is a condition of understanding the moment of viewing as part of a broader visual practice. Cameron Shelley explains this dynamic of images as necessary to imagining visual arguments, in which imitation "reinforces the impression that [images] form a coherent group" (1996, p. 65). Viewers can experience the indexical reduction as complete and accurate only because they understand the reduction as a legitimate visual practice that joins all instances of the template, ichthus or otherwise. We see the ichthus, the 
Darwin fish, and other variants as public identifications.

22 If a position cannot be indexed, it cannot easily be considered publicly. We might think that indexical images would impede public argument by limiting possibilities for nuances. But the contingent reliance of indexical images on public templates and spaces of display actually disclose the deliberative potential of this visual practice. Indexical limits facilitate particular types of public expression, and these can enable rather than impede public argument.

23 The visual practice of indexical identification may be summarized as a series of reductions. With the ichthus, the first indexical identification reduces Christianity to a portable and efficient identification. The second indexing reduces the contrast between Christianity and secularity to a struggle between creationism and evolution (which can occasion several attendant reductions). The third indexing reduces the ichthus from an ideologically invested marker to an empty template for identification. This third condition is crucial, because it opens this indexical template to the entire public. The initial ichthus, the Darwin fish, and the Truth fish confine the visual practice to a single discussion, but the introduction of further ichthus-based markers make the practice less about positions on creationism or evolution - and therefore more available for articulating any brand of (often religious) identity. Cases in point include the Pagan fish,

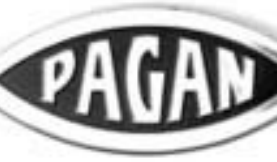

Figure 4

the Buddha fish,

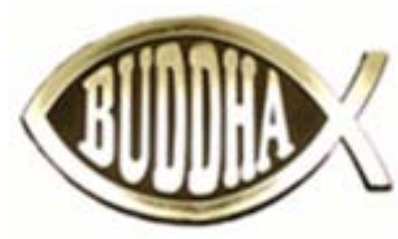

Figure 5

and the somewhat indirect Gifelte fish. 


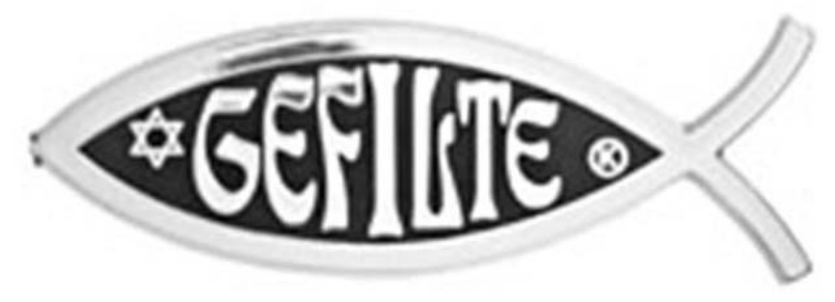

Figure 6

As variations increase, they empty the ichthus further as a template. They strip it of particularity in meaning, investing it instead with the capacity to give meaning to additional variations in this contingent mode of expression.

\section{Fragmented Visual Identity}

24 The increasing variety of ichthus-based indices might tempt us to see this visual practice as purely parodic, but the variety mainly reveals a preference for fragmentation over complexity. If so, why would people prefer the fragmentation? What could be attractive about such a limited, and possibly limiting, mode of public activity? The ichthus often appears on cars these days, and so do magnetic variants of the looped ribbon. To clarify advantages of fragmentation, analyzing a more overtly political index such as the ribbon can be instructive.

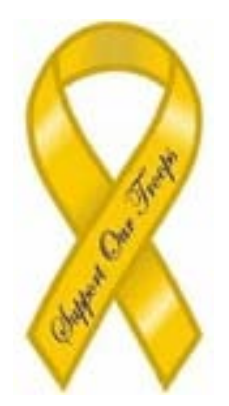

Figure 7

25 The visual practice of placing magnetic ribbons on cars seem to begin with the yellow ribbon that often inscribes the imperative: "Support our troops." Gerald Parsons explains that the yellow ribbon finds its origins in various folk tales about a prisoner looking for a sign that he is welcome back home upon his release. Eventually this legend gains traction as a visual practice for welcoming home in the early 1970s. It becomes explicitly linked to patriotic causes and heroism when used by American families of hostages held by Iran in 1979 (Parsons 2007). The 1991 Gulf War revived the yellow ribbon. It also 
started the proliferation of types that makes the ribbon an indexical template comparable to the ichthus. The looped ribbon is now an easy way to associate yourself with a particular cause, so it invites scrutiny as an activist practice.

26 The ribbon practice of the Iranian hostage era came about as hostage families mobilized their individual displays to a national level. Parsons explains, "With a wonderful exhibition of the spirit that Alexis de Tocqueville thought was a cardinal virtue of our society, the hostage families met and formed an association" (2007). After the hostages returned, the looped ribbon continued to circulate publicly. It manifested troop support in the early 1990s and mutated into the plethora of ribbons at present. Along the way, however, the tie to community action lapsed.

27 Cindy Patton laments the transition to ribbons "as emblems of the citizen who cares deeply about victims (pink for breast cancer, purple for the people of Oklahoma City) but is ultimately unwilling to recognize or fund solutions" (1996, p. 10). This may explain the popularity of magnetic ribbons. Jay Barnes created the website www.antimagnet.com as a visual rejoinder to the magnetic ribbon. Barnes discloses the gap between the visual support through a magnetic ribbon and tangible support through action or money.

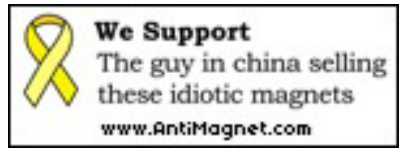

Figure 8

The website proclaims, “We don't hate America, we hate that people think slapping a stupid magnet on the back of their car has meaning. Mostly everyone in this country supports the troops and hopes they will return safely. Maybeyou should be telling them directly in person, on the phone or in a letter and not driving around with a big magnetic banner you probably got at Wal-Mart that simply attempts to prove to everybody but the troops that you support the troops more than everybody else."

28 Ribbon display might have a tenuous tie to contributions of time or money, as Patton and antimagnet complain, but that critique mistakenly separates ribbons from their visual practice. The visual logic of indexical reduction admittedly might flatten support through ribbons, but this implication is only disconcerting if we take the ribbons as meaningful only to the extent that they symbolize tangible forms of activism. The trouble with ribbons as a mode of representation, according to Patton and antimagnet, is that displaying ribbons no longer requires the actual activism to which it merely alludes. 
When critics take images to be wholly, or at least relatively, deficient in accomplishing real support, this assumption becomes an iconoclastic critique of indexical images as a visual practice. The complaint misses how the visual practice of ribbons can communicate something other than support, some other purpose that can only be articulated by a reflective understanding of the display of the ribbons as a visual and social practice.

29 Broad public circulation after the hostage crisis might attenuate ties of ribbons to any particular form of social activism, yet this increases their range of potential causes and uses. As variation produces a more empty and thus flexible and encompassing template, ribbons circulate more widely; as ribbons circulate more widely, the opportunity and incentive increase for variation and further use. The ribbon, even more than the ichthus, becomes a blank template for a great range of causes.

30 The meaning of any one ribbon depends, as it does for any single fish, on contingent relationships between the template and its display spaces.

Ribbons shift from trees and doors at the front of private dwellings to lapels then to automobiles. That transition tells us something about our expectations of visual practices of indexing. Charles Case (1992, p. 107) explains that car bumpers have come to serve as sites for proclaiming beliefs. He argues that this creates a compartmentalized mode of public dialogue. Work by Linda-Renee Bloch (2000, p. 49) on political bumper stickers in Israel encourages us to see driving and traffic as figures of social relationship.

The American penchant for driving and the commuter culture of urban sprawl leave unsurprising the rise of the automobile as a space of visual practice.

31 For Americans, driving is simultaneously public and private. Drivers collaborate in the flow of traffic, interacting physically and visually, yet their cars are security compartments apart from public notice. Anyone who has ever witnessed drivers behaving oddly - singing or talking to themselves, for instance - sees that driving blends privacy and publicity. As cars become spaces for display, the reflective moment of visual display - in choosing to circulate a ribbon - changes the function of the ribbon. No longer marking support or social activism, the ribbon becomes a prominent mode of public identification.

32 That Americans could come to rely on their cars as a mode of public identification is not surprising. As an activity in the interstitial moment between the privacy of individualism and the necessity of public interaction, driving becomes a metaphor for a liberal subjectivity, a political condition when individuals negotiate their unique individual identities alongside their shared, more anonymous public identity. As Michael Warner asserts, current publicity is marked by "deep contradictions between self-abstraction and self- 
realization" that result in "a massive shift toward the politics of identity" (2002, p. 185). To maintain a space of public activity while protecting a sense of individual identity, liberal subjects favor discursive practices that let them articulate a public identity but atomize their private identities to keep those from public scrutiny. The reductive process of indexical images coupled with the circulation through driving provides a visual practice suited to such public activity.

33 This activity is not the kind that Patton and antimagnet want; but it is activity, providing a mode of identification demanded by the recent political climate. Criticisms like Patton's and antimagnet's reveal the anxiety that the practice of indexical identification provokes in groups or individuals who prefer publics shaped by more traditional practices of social activism. Where the visual practice of indexical identification persists, its publics find atomized expression sufficient rather than deficient. Publics find the images to be productive of a particular mode of publicity rather than destructive of all publicity.

34 The literal stickiness of recent ribbons indicates just how fluid the movement between private and public identifications has become. Unlike the permanent adhesion for ichthus variations, car ribbons are magnetic. Displayers concede that their public identities are contingent, temporary, and flexible. The ribbons are in some ways more Tocquevillian than earlier ribbons, because they let individuals enter into public discourse through highly particular identifications then rescind them once the public situation has passed.

35 The public imagination is not the same as that informed by earlier ribbons. Instead these ribbons are ways to enter public life in a time when, as Warner puts it, "To be public in the West means to have an iconicity" (2002, p. 169). The indexical image makes publicity increasingly available to masses, since it allows for meanings to develop through the circumstances of display. It also allows for an increased variety of public identities. The copia of ribbon images lets individuals mark themselves as publicly invested in a huge array of issues. You can support our troops, support bringing them home, or support them by bringing them home. You can support prisoners of war, 


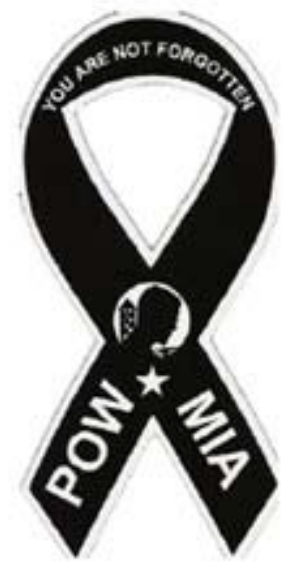

Figure 9

breast-cancer awareness,

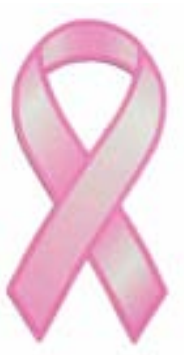

Figure 10

or autism awareness.

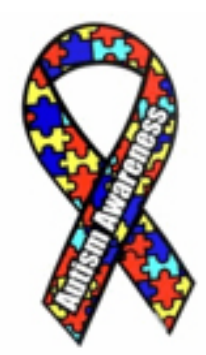

Figure 11

The shift to awareness might suggest that ribbons retain activist potential, but the choice to act by displaying a ribbon might confirm that its function as 
a visual practice is to perform identity more than activism.

36 The plethora of magnetic ribbons reveal that marking yourself as invested in a cause is increasingly popular. Because this occurs in the visual register of the indexical image, the capacity to mark yourself as an invested political subject is seemingly endless yet atomized. The indexical register enables you to be for or against a particular cause, but to invest yourself in another issue would require yet another ribbon. The ribbons illustrate that the complex middle of political discourse is not refused by indexical reduction but fragmented. Such fragmentation is not the end of public deliberation. Instead it is a current condition in a liberal America where the desire to insulate certain characteristics from public scrutiny demands a mode of representing public identities in increasingly reductive and particular ways.

\section{Visual Practice and Political Culture}

37 In the visual practice of the magnetic ribbon, the particularized publicity of identity replaces the complexity of public deliberation. We might worry about the displacement of deliberation, yet the utility of these indexical markers is important for two reasons. First, they offer therapeutic and effective ways to maintain public activity under our conditions of liberalism. Second, the logic of indexical images aligns itself with our political climate, informing a relevant type of subjectivity and creating discursive formations for an increasingly divided body politic.

38 The same goes for the elegantly simple markers of Red and Blue. Indexically these reduce the complexity of political platforms into a simple binary of political identification. Kevin Coe and others (2004, p. 235) argue that our political discourses favor binaries in large measure because simple reductions play well in mass media. Coe and colleagues suggest that binaries "inherently suggest competition between two forces - exactly the sort of conflict that makes for a good news story." They "are stylistically pleasing and therefore supply media outlets with the pithy sound bites that they desire," and they "have moral power, which gives them a resonance with the mass public and a sustaining value" (p. 237). The Red/ Blue binary finds vast circulation because of its easy translation to various media and modes of reporting, but it also resonates with Americans who are conditioned via a visual culture to view such indexical images as complete, accurate, and assuring accounts of the political climate. Like the fish and the ribbons, Red and Blue are popular because their indexical logic matches the cultural logic of politics current in America.

39 Michael Gastner, Cosma Shalizi, and Mark Newman specify a variety of ways to image America after the 2004 presidential election. (Figures 12 through 17 
are available at http:/ / www-personal.umich.edu/ mejn/ election/ .)

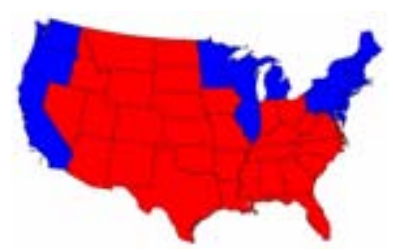

Figure 12

Figure 12 is easily identifiable as a projection map that colors states red or blue for their electoral college results. "The map gives the superficial impression that the 'red states' dominate the country, since they cover far more area than the blue ones. However, as pointed out by many others, this is misleading because it fails to take into account the fact that most of the red states have small populations, whereas most of the blue states have large ones" (2004).

40 A map of population density arguably depicts the election more accurately in Figure 13.

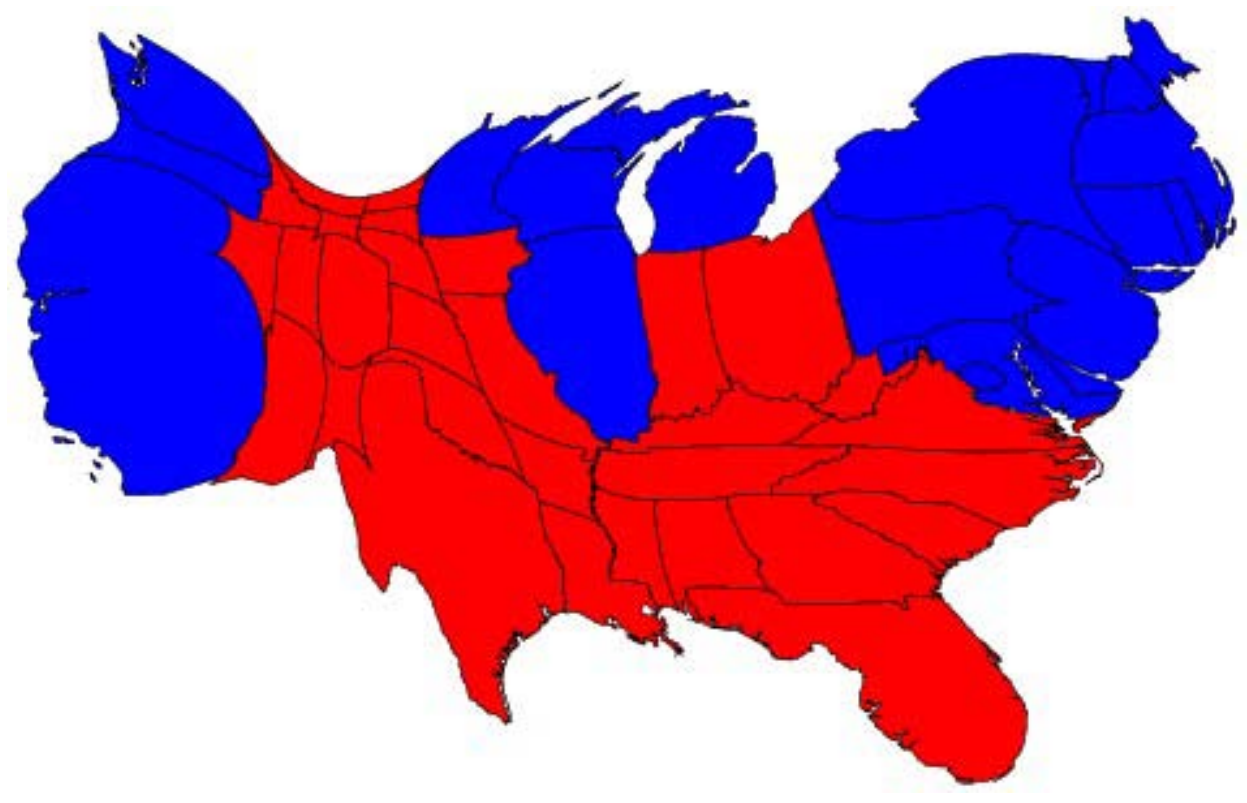

Figure 13

Large patches of blues balance its unified red field. This relies on the simple reduction of red and blue, but it suggests a closer election than the first map.

41 Gastner and others attempt still more accurate depictions of the political 
climate after 2004 through maps of red and blue broken down by county. Figures 14 and 15 show Democratic voters in red states and Republican voters in blue states.

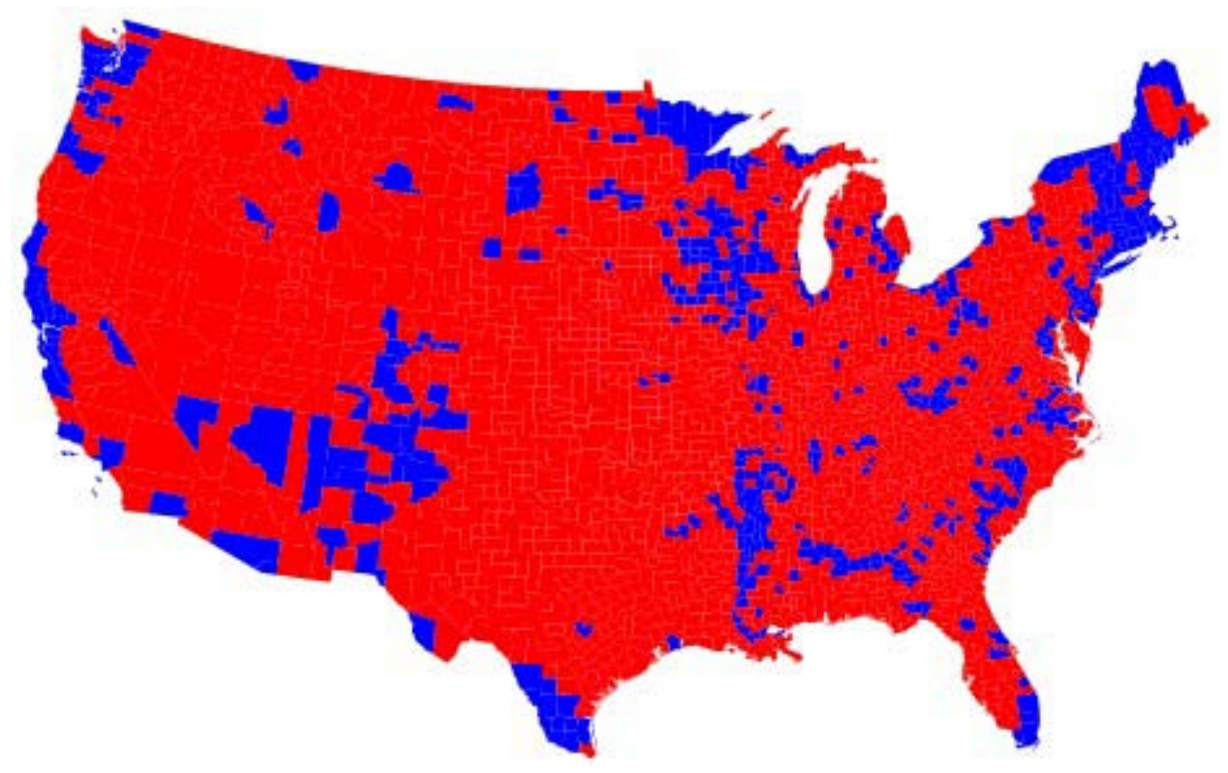

Figure 14

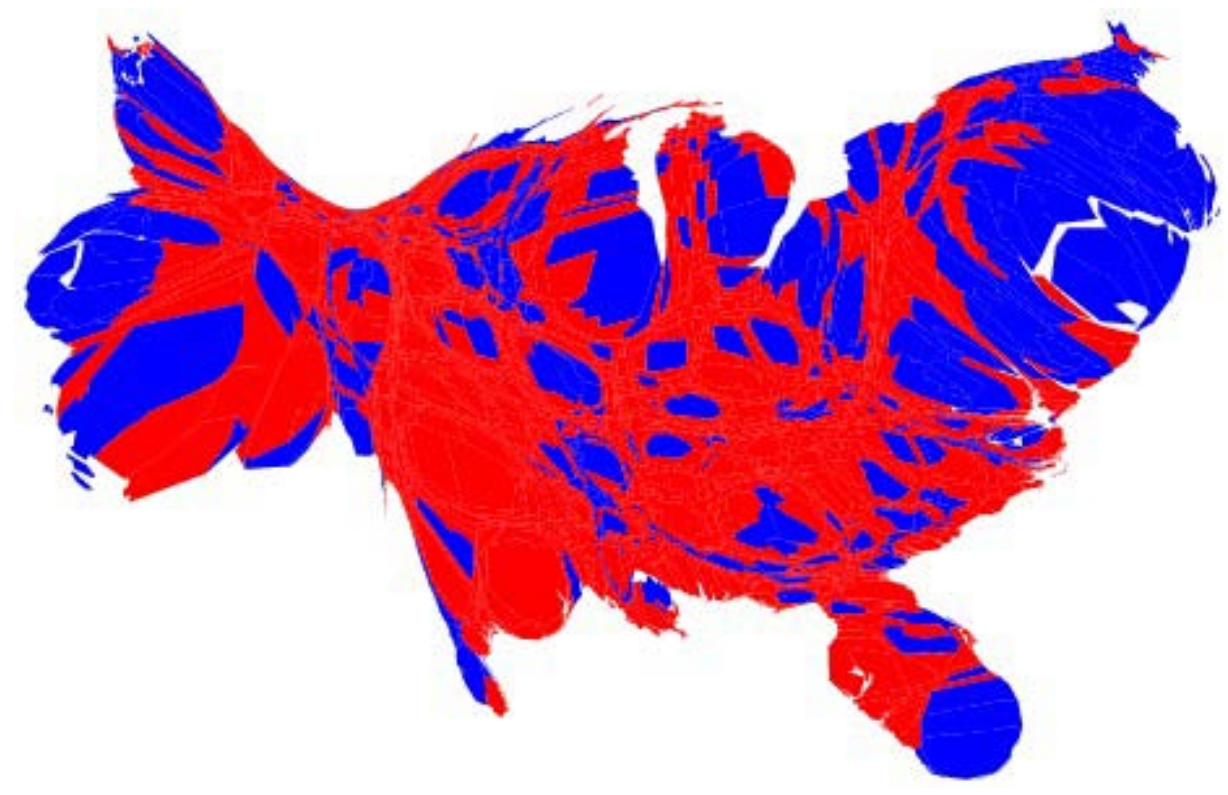

Figure 15

They resemble the state-based maps, indexing either a broadly Republican 
nation or one closely divided.

42 For greater precision, Figures 16 and 17 turn the Red/ Blue binary into a spectrum of colors to indicate voter intensity by county.

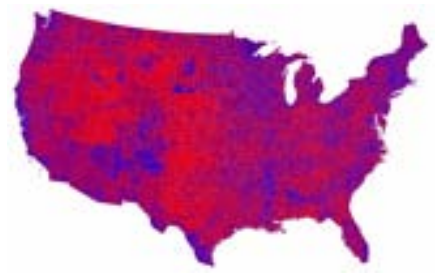

Figure 16

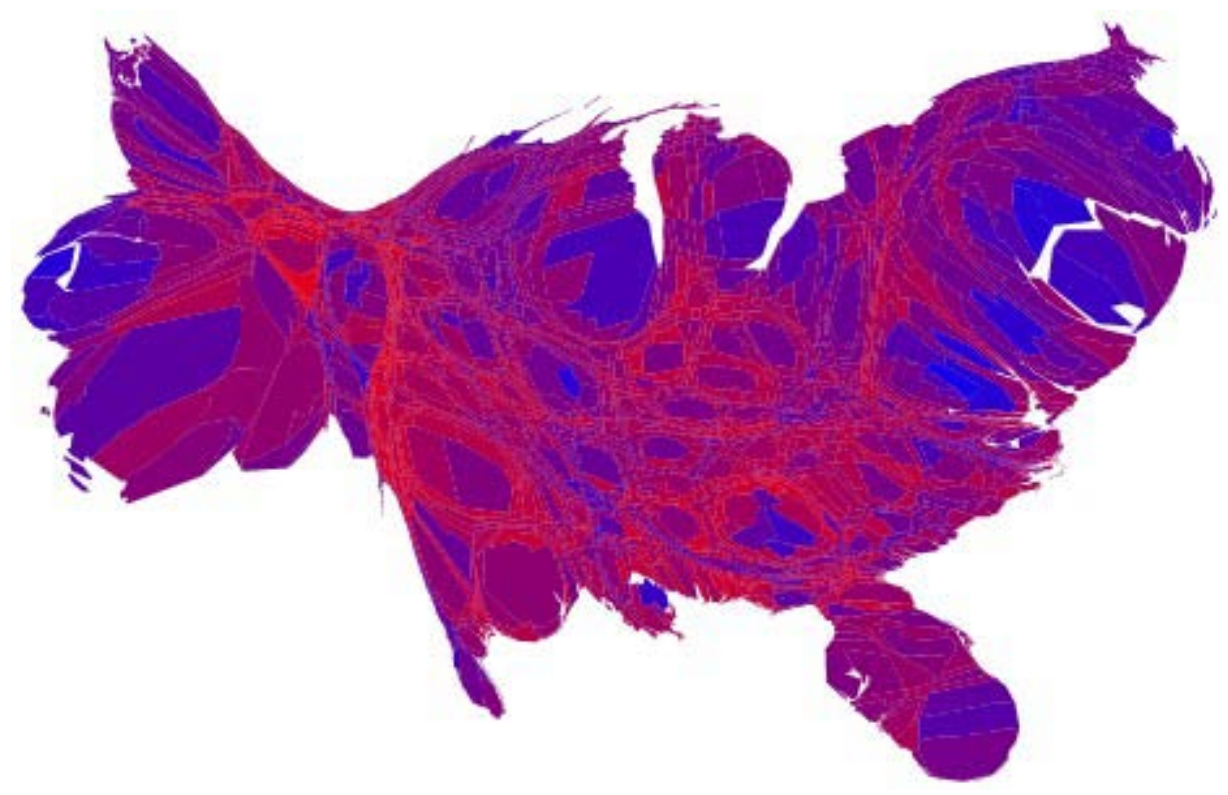

Figure 17

These last two maps manifest the hopeful and inclusive euphemism of Purple America.

43 But Purple America is a false hope, or as Barack Obama would argue, an audacious hope. In his Democratic Convention keynote (2004), Obama denounced Red and Blue as divisive of the e pluribus unum of America; whereas Purple America combines Red and Blue so intricately that neither indexical reduction stays distinct. Obama is right that the Red/ Blue binary divides, but he neglects its therapeutic insulation of private identity. Obama has had great success arguing for a hopeful Purple America, but we might 
wonder if his appeal can succeed in the face of the differentiating and isolating logic of visual indexing However precise or unifying Purple America might be as a concept, as a visual marker, it suffers several problems in the context of our visual practices.

44 Whereas Coe and others evoke a technological explanation of binaries, Obama attributes the Red/ Blue binary to "the spin masters, the negative ad peddlers who embrace the politics of 'anything goes'" (2004). Yet the Red/ Blue binary comes mainly from the operational logic of the electoral college and the prominence of only two parties in American politics. The idea of Purple America refuses both. Useful as Figures 14-17 may be for explaining our political climate, they explain little about the 2004 election. In the electoral college, each state voted for the Democratic or the Republican candidate, marking each state as red or blue. We could index other candidates in other colors, such as Ralph Nader in Green, but this may be as misleading as Purple: no state voted that way, and subsequent politics did not work that way. Purple America stands alongside Obama's proclamation that "there is not a liberal America and a conservative America - there is the United States of America" (2004). It would replace the simplicity and precision of Red/ Blue with an image of complexity that violates the dominant logics of electoral politics as well as visual indexing current in America.

45 The complexity implied by Purple America also subverts our visual practices of public identity. Purple America may index a hope for public activity that results in compromise, but the prevalence of indexical reductions leaves the utility of the image suspicious. If there can be no purple state in the electoral college, can there be a purple voter? The stakes of identifying with the red candidate or the blue are too high to treat the identification as incidental. When every vote counts, as it can in a country split down the middle, the idea of the middle - of purple - implies a space for complex public identification. Can this remain in a world where indexical reductions have formative effects on political affiliations?

46 As a representation of complexity, Purple America refuses the insulation guaranteed by indexical identifications. Our citizenship is complicated; and Obama is correct when he asserts, 'We worship an 'awesome God' in the Blue States, and we don't like federal agents poking around in our libraries in the Red States. We coach Little League in the Blue States and yes, we've got some gay friends in the Red States" (2004). But Purple America would make private enjoyments like coaching Little League into political spectacles. Anything can be politicized; but in our practice, citizens compartmentalize their private interests and selectively expose their public concerns. Thus they mark themselves as invested in our troops by slapping ribbons on their cars then privately singing along with the radio inside. 
47 If the U.S. citizen is a liberal subject in the sense of a private individual with rights and protections, and if this subject exists in a mediated environment that replaces localized publicity with mass publicity, the nuance of Purple America is a mistake. It ignores the atomization of political action encouraged by fragmented identification and informed by the political activities in visual culture. There is no purple state, there is no purple voter, and (it seems possible at this point that) there is no purple politics. These are less results of a two-party system than of the increasingly fragmented ways that individuals enter public life through identificatory politics.

\section{Politics in an Age of Fragmentary Images}

48 This relationship between visual and political practices can be summarized in three steps. Mass publicity in America encourages indexical displays as moments of political identification and activity. At moments of display, indexical images invest viewers in a presumed performance of reduced completeness, with current mechanics and conditions of American politics increasing traction for such identification. All this makes the visual practice of indexical images significant less for the meaning of any specific fish or ribbon than for the indexical discourse in its overall variety and circulation. The result is a particularly fragmented mode of public imagination.

49 The fragmentation need not destroy publicity; rather it enables the practice to adjust itself to our particular political moment. Dana Cloud argues that politicized images function as metonymic moments when reproducing images to circulate them can perform a type of public work. Looking at images of Afghani women following September 11, 2001, she suggests that 'Metonymizing the conflict in terms of 'our way of life' and challenges to it reduces a complex set of geopolitical motives, strategies, and outcomes to a cultural binary" (2004, p. 291).

50 Cloud notes two potential problems with visual metonyms. Because they stand for much more complicated issues, such reductions can make nuance and subtlety difficult. To bracket complexity might be therapeutic, but Cloud articulates an instance where reduction impedes needed complexity. A second problem is that visual reductions can favor the polarizing discourse of binaries. Yet binaries might result not from polarization but instead from limited, underdeveloped spaces for visual display. The ichthus and ribbons show that, once opened and normalized, circulation spaces can sustain many images that turn the polarizing discourse of the binary opposition into a field of exceedingly particular yet exceedingly various images. While the Red/Blue index seems binary, its opposition stems less from visual practices than institutional structures. Thus it seems possible that Cloud's reductive binary results, not from a visual tendency to reduce things to two sides, but from an institutional resistance to multiple images that would disperse binaries into a 
variety of particularized positions.

51 Cloud argues that the images of Afghani women "do not state the ideograph $<$ clash of civilizations $>$ as much as they become the clash in visual condensations of the meanings of 'American' and 'Other'” (p. 291). Likewise indexical identifications do not merely represent support for particular causes; rather they are ways to enter public life through identifications. The question that remains to be asked of this visual practice is how the introduction of various atomized identifications can remain particular and isolated in circulation spaces that brim with variety: How do particular moments of identification resist becoming a composite identity?

52 Visual images, and especially photographs, have great discursive utility because their various inventional strategies "are masked by the appearance of having captured reality" (p. 289). However, the appearance is less of a representational continuity with reality than of a totalizing containment of experience. Individuation and display of indexical images encourage us to see them in an isolation marked by the space where the display ends. This gives us a sense of experiencing an image in its totality. When we see several ribbons on a car, we still can - and often do - see each ribbon in isolation. The presumed completeness of a visual image makes for a metonymic moment that seems to isolate a particular expression as a complete depiction. Your decision to display a specific ribbon or other indexical marker is a decision to offer up this one, fragmented identification as the totality of your public identity.

53 The reduction and fragmentation of political positions by indexical images can suggest a quasi-logical, pseudo-deductive moment of political argument. As Chaim Perelman and Lucy Olbrechts-Tyteca explain, "What characterizes quasi-logical argumentation, therefore, is its nonformal character and the effort of thought which is required to formalize it" (1969, p. 193). The images are informal operations of identification. As Gadamer (2000) and Lacan (1981) suggest, though, we experience in such visual objects a formal completeness. As simple markers circulated in public space, consequently, indexical images can encourage a vaguely positivist relationship to public identity. To see or display a visual marker is to encounter evidence of a public identity. To the extent that the visual experience is self-contained and complete, so is the public identity.

54 The presence of such quasi-logical arguments in traditional political discourse bolsters this pseudo-deductive logic, and it prepares viewers for other quasi-logical arguments. To see this reciprocity at play, recall President Bush's faux categorical syllogism from his "Address to a J oint Session of Congress and the American People" on September 20, 2001: "Either you are with us, or you are with the terrorists." This is binary, and it polarizes, but it 
also simplifies a complex political argument in much the same way that a visual index can reduce complicated political activity into a simple moment of precise identity. As Coe and colleagues note, it is crucial that Bush relies not on one binary but many. "Although a single binary has significant rhetorical power, multiple binaries allow a speaker to make strategic decisions and respond to multiple exigencies" (2004, p. 236). Multiple binaries can work like the pluralizing spaces of fragmented positions created by indexical images, so we may expect indexical logics in many public discourses. Multiple binaries can work well for us because they can imply a deductive completeness that resonates with American citizens who mark themselves as political subjects in similarly reductive and seemingly complete ways. Our complexity of public life is less about negotiating and integrating a range of discourses and more about itemizing and moving fluidly among a wide variety of increasingly particular and atomized positions.

\section{The Indexical Imaginary}

55 The prominence of the visual practices of indexical images presents us with a conundrum. Do indexical practices fragment our public discourses, or do fractious politics fragment our visual practices? Most likely, our politics and images reinforce each other and the homologies between the two enable rhetorical scholarship to benefit from visual research. Beyond flashy slideshows arise accounts of address that can inform our conceptions of public discourse and explain the resonance of some appeals and arguments.

56 To see how indexical reduction is more than a sidebar for public discourse, turn to the courtroom, where visual practices are altering legal strategies of argument. Prosecutors now complain about the "C.S.I. Effect" and the "C.S.I. Syndrome." C.S.I. is a popular franchise of television programs on CBS. The hour-long dramas depict crime-scene investigators who catch and convict criminals with cutting edge, visually stimulating technology. Kit Roane reports, "Stoked by the technical wizardry they see on the tube, many Americans find themselves disappointed when they encounter the real world of law and order. J urors increasingly expect forensic evidence in every case, and they expect it to be conclusive" (2005, p. 48). As a result, visual analogues of forensic evidence are becoming more prominent in the courtroom.

57 The C.S.I. Effect is a discursive end-game for a culture that features simplifying images. Medical forensics are complicated, yet the visual images on C.S.I. suggest complete and concise assertions. The quasi-logical experience of such visual evidence promotes a simple positivism. "Scientists figure as disembodied intellects making knowledge in a field of facts and observation (and language, as the reflexivists remind us). But there is quite another way of thinking about science. One can start from the idea that the 
world is filled not, in the first instance, with facts and observations, but with agency. The world," Andrew Pickering argues, "is continually doing things, things that bear upon us not as observation statements upon disembodied intellects but as forces upon material beings" (1995, p. 6). As evidence, C.S.I. images make indexical reductions; but they simplify scientific arguments rather than public identities.

58 Scientists experience medical forensics through complex machinery, then jurors mimic the process by experiencing an image that is supposed to offer the heft of scientific proof without the burden of specialized knowledge. Scott Grafton and colleagues caution that, "when a new scientific procedure is first admitted in trials as evidence, there is significant risk that lay juries and judges will overestimate the value of that evidence. This danger is especially high when the procedure involves eye catching pictures presented by scientists with impressive credentials" (2007, p. 36). Such visual practices inform courtroom discourse, with prosecutors and defense attorneys alike recognizing the force of visual address. They align brain scans or fingerprints to show contrasts and commonalities. Even when jurors do not know what different shadows show on brains scans or what operations lead forensic scientists to place dots on fingerprints, jurors can recognize visual differences and similarities. Experiencing such images, they enter into a performance of science that can seem conclusive because the visual experiences are totalizing. The C.S.I. Effect hints at how pervasive visual indexing has become for us. We want visually conclusive evidence, and we take evidence to be conclusive merely because it is visual.

59 The C.S.I. Effect connects readily to the culture industry as analyzed by Max Horkheimer and Theodor Adorno. "The more intensely and flawlessly [the producer's] techniques duplicate empirical objects," they explain, "the easier it is today for the illusion to prevail that the outside world is the straightforward continuation of that presented on the screen" (1976, p. 126). Yet this ignores the vibrant public activity of indexical identification, which boosts the demand for visual images in public discourse. The public does not want visual images merely because they appear on television but because they are a primary way to represent the complexity of public life in simple terms.

60 The brisk movement from fish to ribbons to maps to political and legal discourses gives shape to an indexical imaginary. The indexical seems prevalent in our public imagination. It enables public identification and informs public discourse, always in a particularlizing way. To the extent that Americans experience public life in increasingly fragmented spaces, such visual expression allows for atomized identification. It also supports increasingly reductive and precise modes of public discourse, which sometimes enlist the visual practice of the indexical image. The reductions can create problems, especially when complexity and nuance are helpful. At 
times, though, the reductions are off-set by the ensuing copia of fragmented discourses. Magnetic ribbons show this. At other times, moreover, the reductions serve the public by creating insulated spaces for private identification.

61 Whatever the gains and losses in specific visual and discursive practices, the indexical imaginary reveals how the visual and the more traditionally discursive can coexist, reinforce, and even merge with each other. Because visual practices and public discourse inform each other in telling ways, rhetoricians need not reformulate publicity to make room for visual discourse. In fact, to look at individual images rather than their visual practices can be to miss the homologous logical operations that inform both areas of expression. As Roane says, "Everyone, including the jury, wants certainty. But it seldom exists in forensics" (2005, p. 48). The prominence of indexical images offers this certainty, not just in the courtroom, but in public life.

62 The desire to see tangible, conclusive proof may be a result of the influence of fictional forensics, but it may also have roots in the desire for public moments to be concise, complete, and atomized from private concerns. In a public increasingly marked by fewer and fewer traditionally deliberative moments, a public whereby our political discussions have been reduced to brief moments of limited identification in the few spaces that are experienced publicly, moments of civic participation may be increasingly informed by the logic of the indexical image. This is particularly true when images are present, but it also seems true in more traditional deliberative venues, because the logic of the indexical image so closely aligns itself with the modes of address contemporary American citizens seem to demand from their public discourse.

(c) Brett Ommen, 2008.

\section{References}

Benjamin, Walter. 1999. The Arcades Project, Howard Eiland and Kevin McLaughlin, tr. Cambridge: Belknap Press.

Bloch, Linda-Renee. 2000. "Mobile Discourse: Political Bumper Stickers as a Communication Event in Israel." J ournal of Communication, 50, 2, pp. 48-76.

Bush, George W. 2001. "Address to a J oint Session of Congress and the American People." Washington, DC, September 20, http:/ / www.whitehouse.gov/ news/ releases/ 2001/ 09/ 200109208.html. 
Case, Charles. 1992. "Bumper Stickers and Car Signs Ideology and Identity." J ournal of Popular Culture, 26, 3, pp. 107-119.

Caton, Steven C. 1987. "Contributions of Roman J akobson." Annual Review of Anthropology, 16, pp. 223-260.

Cloud, Dana. 2004. “To Veil the Threat of Terror': Afghan Women and the Clash of Civilizations in the Imagery of the U.S. War on Terrorism." Quarterly J ournal of Speech, 90, 3, pp. 285-306.

Coe, Kevin, and others. 2004. "No Shades of Gray: The Binary Discourse of George W. Bush and an Echoing Press." J ournal of Communication, 54, 2, pp. pp. 234-252.

Finnegan, Cara and Jiyeon Kang. 2004. "'Sighting' the Public: Iconoclasm and Public Sphere Theory." Quarterly J ournal of Speech, 90, 4, pp. 377-402.

Gadamer, Hans-Georg. 2000. "Aesthetics and Hermeneutics," David E. Linge, tr. The Continental Aesthetics Reader, Clive Cazeaux, ed. London: Routledge.

Gastner, Michael, Cosma Shalizi, and Mark Newman. 2004. "Maps and Cartograms of the 2004 U.S. Presidential Election Reesults." November 17, http:// www-personal.umich.edu/ mejn/ election/ .

Grafton, Scott T., and others. 2007. "Brain Scans Go Legal.” Scientific American Mind, December 2006 - J anuary 2007, pp. 30-37.

Hariman, Robert, and J ohn Lucaites. 2002. "Performing Civic Identity: The Iconic Photograph of the Flag Raising on Iwo J ima." Quarterly J ournal of Speech, 88, 4, pp. 363-392.

Horkheimer, Max, and Theodor W. Adorno. 1976. The Dialectic of Enlightenment, J ohn Cumming, tr. New York: Continuum.

Lacan, J acques. 1981. The Seminar of J acques Lacan, BookXI: The Four Fundamental Concepts of Psychoanalysis, J acques-Alain Miller, ed., Alan Sheridan, tr. New York: Norton and Company.

Lessl, Thomas M. 2007. "The Culture of Science and the Rhetoric of Scientism: From Francis Bacon to the Darwin Fish." Quarterly J ournal of Speech, 93, 2, pp. 123-149.

Obama, Barack. 2004. "The Audacity of Hope." Democratic Convention Keynote Address, Boston, July 27, 
http:// www.americanrhetoric.com/ speeches/ convention2004/ baracko bama2004dnc.htm.

Parsons, Gerald E. 1991. "How the Yellow Ribbon Became a National Folk Symbol.” Folklife CenterNews, 13, 1, pp. 9-11.

Patton, Cindy. 1996. Fatal Advice: How Safe-Sex Education Went Wrong. Durham: Duke University Press.

Peirce, Charles S. 1940. Philosophical Writings of Peirce, J ustus Buchler, ed. New York: Dover.

Perelman, Chaim, and Lucy Olbrechts-Tyteca. 1969. The New Rhetoric, J ohn Wilkinson and Purcell Weaver, trs.. Notre Dame, IN: University of Notre Dame Press.

Pickering, Andrew. 1995. The Mangle of Practice: Time, Agency, and Science. Chicago: University of Chicago Press.

Roane, Kit. 2005. “The CSI Effect.” U.S. News and World Report, April 25, p. 48.

Shelley, Cameron. 1996. "Rhetorical and Demonstrative Modes of Visual Argument: Looking at Images of Human Evolution." Argumentation and Advocacy, 33, 1, pp. 53-68.

Story, Louise. 2007. “Anywhere the Eye Can See, It's Now Likely to See an Ad." New York Times, J anuary 15, section A.

Taylor, Charles. 2002. “Modern Social Imaginaries.” Public Culture, 14, 1, pp. 91-124.

Warner, Michael. 2002. Publics and Counterpublics. New York: Zone Books.

Williams, Phil. 1999. "Capture The Flag: Darwin Fish' May Be a New Version of Very Old Game, University of Georgia Study Proposes." September 21, http:// www.uga.edu/ news/ newsbureau/releases/ 1999releases/ darwinf ish.html.

www.antimagnet.com. Accessed 2 February 2007. 